\title{
Antibacterial, antifungal and antioxidant activities of bee glue ethanol and aqueous extracts
}

\author{
Nabi Shariatifar, ${ }^{1}$ Akram Janghorban, ${ }^{2}$ Rezvan Rahimnia, ${ }^{3}$ Amir Sasan Mozaffari Nejad ${ }^{4}$ \\ ${ }^{1}$ Department of Environmental Health, School of Public Health, Tehran University of Medical Sciences, Tehran; \\ ${ }^{2}$ Department of Food Industry, Islamic Azad University, Science and Research Branch, Tehran; ${ }^{3}$ Department of \\ Environmental Education, School of Humanities, Payame Noor University, Tehran; ${ }^{4}$ Nutrition Health Research \\ Center, Student Research Center, Hamadan University of Medical Sciences, Hamadan, Iran.
}

\begin{abstract}
Food-borne pathogens is a group of micro-organisms that cause food-borne illness, thus the research for finding effective drugs against this infection is necessary. The purpose of this study determines antibacterial, antioxidant activity antifungal of bee glue ethanol and aqueous extracts. Antibacterial and antifungal activities of extracts were evaluated against food-born (Escherichia coli, Staphylococcus aureus, Bacillus cereus, Vibrio cholerae and Candida albicans) purchased from Boali hospital on by the well diffusion method. Broth serial dilution method was doing to find the Minimal Inhibitory Concentration (MIC) and the agar dilution method to find the Minimal Bacterial Concentration (MBC) of extracts. The antioxidant activity of the extracts assaying by 2,2-diphenyl-1-picrylhydrazyl (DPPH) method. Ethanol extract of bee glue was found the most effective against $S$. aureus strains (inhibition zone $=27 \pm 0.87 \mathrm{~mm}$ ) than $E$. coli strains (inhibi-
\end{abstract}

Correspondence: Amir Sasan Mozaffari Nejad, Hamadan University of Medical Sciences, Hamadan, Iran.

E-mail: as.mozafarinejad@umsha.ac.ir

Key words: Bee glue, antioxidant activity, antimicrobial activity, extract.

Contributions: the authors contributed equally.

Conflict of interest: the authors declare no potential conflict of interest.

Acknowledgements: the authors would like to acknowledge the financial support of the Food Safety and Chemical Research Center, Tehran University of Medical Science, Iran.

Received for publication: 7 December 2016.

Revision received: 25 April 2017.

Accepted for publication: 5 May 2017.

(C) Copyright N. Shariatifar et al., 2017

Licensee PAGEPress, Italy

Journal of Biological Research 2017; 90:6452

doi:10.4081/jbr.2017.6452

This article is distributed under the terms of the Creative Commons Attribution Noncommercial License (by-nc 4.0) which permits any noncommercial use, distribution, and reproduction in any medium, provided the original author(s) and source are credited. tion zone $=5.5 \pm 0.37 \mathrm{~mm}$ ). Aqueous extract of propolis was found the most effective against $S$. aureus strains (inhibition zone $=14.5 \pm 0.75 \mathrm{~mm}$ ) than $E$. coli strains (inhibition zone $=3.5 \pm 0.5 \mathrm{~mm}$ ) and $C$. albicans (inhibition zone $=10 \pm 0.5 \mathrm{~mm}$ ). The MIC and MBC values of the extracts ethanol and aqueous most effective against $B$. cereus strains were $0.3125,0.625$, 0.3125 and $1.25 \mathrm{mg} / \mathrm{mL}$ than E. coli strains $0.625,1.25,2.5$ and $50 \mathrm{mg} / \mathrm{mL}$. and also for C. albicans was $0.625,1.25,1.25$ and 2.5 $\mathrm{mg} / \mathrm{mL}$. IC50 ethanol and aqueous extracts of propolis were $8 \pm 0.25$ and $45 \pm 1.75$, respectively. This study was to assess the Antibacterial, antifungal and antioxidant activities activities of bee glue extracts in in vitro.

\section{Introduction}

The honey bees can be considered as the collect bee glue from plant resin through biting off scraps. Bee glue is hard and fragile at room temperature and soft, malleable and sticky when heated. It can be extracted by the honey bees from the resin of plants in the inside of bee nest and used to repair honeycombs, and keep up disinfection of the beehive, prevent decay organisms inside the bee nest that dies..$^{1,2}$ Furthermore, the variation in the composition of bee glue can be associated with the plant species, regional geography, and seasons, which were visited by the honey bees as well as the metabolized and secreted substances by them and also further added components during its production. ${ }^{3}$

Some biological properties such as antioxidant, antifungal, and antimicrobial activity, mainly due to of phenolic compounds, especially flavonoids, were demonstrated previously. ${ }^{4-6}$ Moreover, recently, the utilization of natural preservative ingredients such as natural waxes, plant extracts and essential oils in order to inhibition of growth of foodborne pathogens as well as spoiling molds in food products is highly regarded..$^{7-8}$ Due to favorable properties, bee glue can be utilized in variety of applications, such as anti-wrinkle, anti-acne, anti-inflammatory, antiviral, anti-diabetic and leishmanicidal agents. ${ }^{9-17}$ In addition approaching of extracted bioactive compounds from medicinal plants sources as antimicrobial and antioxidants agents attracted notable attention. ${ }^{18,19}$ In this context, the bee glue extracts can be incorporated in food processing, nutraceuticals or cosmetic antiaging formulations.

Hence, the goal of this study was undertaken to assess the antioxidant and/or antimicrobial activities of bee glue extracts an in vitro system. 


\section{Materials and Methods}

\section{Preparation of extracts}

Bee glue samples were collected from reclaimed land at Kandovan of Tabriz province, Iran 2012 and stored for 3 months at $20^{\circ} \mathrm{C}$. Ten gram of sample and divided into two equal parts, each of them was cut into small pieces and extracted at room temperature with $100 \mathrm{~mL}$ of $80 \%$ ethanol (twice after $24 \mathrm{~h}$ ) for ethanol extract and with $100 \mathrm{~mL}$ of water distillates (twice after $24 \mathrm{~h}$ ) for water extract. The extracts evaporated under vacuum at $50^{\circ} \mathrm{C}$ until dryness.

\section{Isolation and identification of Candida albicans}

Candida albicans isolates was recovered from women with vaginitis attended to Yas Moheb hospital, Tehran, Iran. Swabs were taken from patient by using sterile cotton swabs with transport media. The samples were cultured on Sabouraud dextrose agar supplemented with chloramphenicol to prevent bacterial contamination and incubated at $37^{\circ} \mathrm{C}$. The fungal culture was examined according to the colonies, cellular morphology and germ tube formation.

\section{Disk diffusion test}

The aqueous extracts were tested against Staphylococcus aureus ATCC 25913, Escherichia coli ATCC 8739, Bacillus cereus PTCC 1709 and Vibrio cholerae PTCC 1611. The microorganisms were cultured in BHI (Brain Heart Infusion) for 18 hours at $37^{\circ} \mathrm{C}$, and resuspended in 0.5 MacFarland Standard $\left(5 \times 10^{8} \mathrm{CFU} / \mathrm{mL}\right)$ and inoculated directly in boards with Mueller-Hinton Agar (Merck). After inoculation of each microorganism, the diffusion method was used, putting $10 \mu \mathrm{L}$ of essential oil on paper disks ( $6 \mathrm{~mm}$ of diameter) at $37^{\circ} \mathrm{C}$ for 24 hours, after which time the zone of inhibition were measured. Triple plates were used for each concentration. ${ }^{20,21}$

\section{Determination of antimicrobial activity by agar diffusion method}

Petri plates containing $25 \mathrm{~mL}$ of Mueller-Hinton agar for bacteria and Sabouraud dextrose agar for C. albicans were used. Agar media were seeded with a $24 \mathrm{~h}$ old culture of the microorganism strains (by sterile cotton swab dipped into the broth of these microorganisms). Four wells (5 mm diameter) were cut into the agar by cork borer and $0.1 \mathrm{~mL}$ of the crude bee glue extracts was applied in each well. The inoculums size was adjusted so as to deliver final inoculums of approximately $10^{8}$ colony forming unit $(\mathrm{CFU}) / \mathrm{mL}$, compared with the turbidity of a sample of the 0.5 McFarland standards. Incubation was performed at $37^{\circ} \mathrm{C}$ for $24 \mathrm{~h}$. The assessment of antibacterial and antifungal activity was based on measurement of the diameter of the inhibition zone formed around the well. Streptomycin was used as a reference antibacterial agent and nystatin as a reference antifungal agent. ${ }^{22}$

\section{DPPH assay}

The hydrogen atom or electron donation abilities of the corre- sponding extracts and some pure compounds were measured from the bleaching of the purple-colored methanol solution of 2, 2diphenyl-1-picrylhydrazyl (DPPH). This spectrophotometer assay uses stable radical DPPH (Sigma, Aldrich) as the reagent. ${ }^{23}$ Briefly, $50 \mu \mathrm{L}$ of the extracts (various concentrations) were added to $5 \mathrm{~mL}$ of the DPPH solution ( $0.004 \%$ methanol solution). After $30 \mathrm{~min}$ incubation at room temperature, the absorbance was read against pure methanol at $517 \mathrm{~nm}$. The radical-scavenging activities of the samples were calculated as percentage of inhibition according to the following equation:

$$
\begin{gathered}
\text { \% DPPH radical scavenging= } \\
{[(\text { control absorbance (blank) }- \text {-sample absorbance }) /} \\
(\text { control absorbance })] \times 100
\end{gathered}
$$

Extract concentration providing 50\% inhibition (IC 50) was calculated from the plot of inhibition percentage against extract concentration. All tests were done in triplicate. Values (mean $\pm \mathrm{SD}$ ) of the extracts were compared with those of BHT using student's t-test. A $\mathrm{P}$ value less than 0.05 were statistically considered significant. ${ }^{24}$

\section{Statistical evaluation}

All analyses and results were presented as mean \pm standard deviation. The statistical analyses of data were performed by using SPSS version 16.0 (IBM SPSS Inc., Chicago, IL). $\mathrm{P}<0.05$ was considered as the significant difference.

\section{Results and Discussion}

Susceptibility test by broth and agar micro dilution or bee glue extracts were performed. The Minimal Inhibitory Concentration (MIC) e Minimal Bacterial Concentration (MBC) value of bee glue aqueous and extracts For Staphylococcus aureus, E. coli, Vibrio cholerae and Bacillus cereus showed in Table 1 . The Table 2 shows antimicrobial activity ethanol extract of bee glue against the all the bacterial strains, used in this study (S. aureus, E. coli, V. cholerae and B. cereus with an inhibitory zone of $27 \pm 0.87 \mathrm{~mm}, 5.5 \pm 0.37 \mathrm{~mm}, 20 \pm 1.04 \mathrm{~mm}, 21 \pm 1.32 \mathrm{~mm}$, respectively). The Table 3 shows antimicrobial activity aqueous extract of bee glue against the all the bacterial strains, used in this study (Staphylococcus aureus, E. coli, Vibrio cholerae and Bacillus cereus with an inhibitory zone of $14.5 \pm 0.75 \mathrm{~mm}, 3.5 \pm 0.5 \mathrm{~mm}$, $14 \pm 1.30 \mathrm{~mm}, 5.5 \pm 0.32 \mathrm{~mm}$, respectively. According to the results (Tables 1 and 2) extracts of bee glue revealed much antimicrobial activity against some food pathogenic bacteria. Antibacterial susceptibility was evaluated using classical microbiological techniques with disk diffusion, MIC and MBC determination.

The Table 4 shows antioxidant activity ethanol and aqueous extracts. In this study antioxidant activity was measured and compared with that of butylated hydroxytoluene (BHT) using DPPH

\begin{tabular}{|c|c|c|c|c|c|c|c|c|c|c|}
\hline \multirow[t]{2}{*}{ Test } & \multicolumn{2}{|c|}{ S. aureus } & \multicolumn{2}{|c|}{ V. cholera } & \multicolumn{2}{|c|}{ B. cereus } & \multicolumn{2}{|c|}{ E. coli } & \multicolumn{2}{|c|}{ C. albicans } \\
\hline & Aqueous & Ethanol & Aqueous & Ethanol & Aqueous & Ethanol & Aqueous & Ethanol & Aqueous & Ethanol \\
\hline MIC $(\mu \mathrm{g} / \mathrm{mL})$ & 1250 & 625 & 1250 & 312 & 625 & 312.5 & 1250 & 625 & 1250 & 625 \\
\hline $\mathrm{MBC}(\mu \mathrm{g} / \mathrm{mL})$ & 2500 & 1250 & 1250 & 625 & 1250 & 312.5 & 50000 & 2500 & 2500 & 1250 \\
\hline
\end{tabular}
method. The high absorbance values indicated that the sample pos-

Table 1. Determination of MIC and $\mathrm{MBC}$ value $(\mu \mathrm{g} / \mathrm{mL})$ for aqueous and ethanol extract of propolis against microorganisms. 
sessed significant antioxidant activity. According to the result (Table 4), there was significant difference between antioxidant activity of ethanolic and aqueous extract of bee glue. Also there were significant differences between extracts and BHT $(\mathrm{P}<0.05)$.

The scavenging activity on DPPH radicals has been widely used by scientists to determine the free radical-scavenging activity; therefore we study the antioxidant activity of the extracts of bee glue using DPPH method. The extracts exhibited a remarkable anti-oxidant activity (LC50 $=8 \pm 0.25 \mu \mathrm{g} / \mathrm{mL}$ and $45 \pm 1.75 \mu \mathrm{g} / \mathrm{mL}$ ).

Many results found by several researchers have shown that extracts of bee glue have effect antibacterial and antioxidant. A research report by Musa et al. (2012) showed that antibacterial activity of propolis (bee glue) ethanolic extract more effective than aqueous extract. ${ }^{25}$ Also, the previous survey by da Silva et al. (2010) reported that antibacterial activity of propolis methanolic extract more effective than ethanolic extract. ${ }^{26}$ The similar conducted study by Cottica et al. (2011) reported that antioxidant activity low ethanol content extracts more effect than pure ethanol extract. ${ }^{27}$

The previous study by Hegazi and Abd El Hady (2002), showed that antioxidant activity of Propolis samples. El-Saff propolis had a higher antioxidant activity than Ismailia propolis, while the Ismailia propolis had a higher antibacterial activity against E. coli, than El-Saff propolis. ${ }^{28}$

According to a number of different studies was performed by other scientists, phytochemical compound that present in propolis extracts such as phenolic compounds and flavanoids can to associated with antioxidant and antibacterial activity. ${ }^{29}$

Table 2. Comparison of average inhibitory halo diameter $(\mathrm{mm})$ of various bacterial strains for ethanol extract of Propolis.

\begin{tabular}{lcccc} 
Bacterial strain & Samples & Min & Max & Mean \pm SD \\
Staphylococcus aureus & 3 & 26 & 28.5 & $27 \pm 0.87$ \\
Escherichia coli & 3 & 4.5 & 6 & $5.5 \pm 0.37$ \\
\hline Vibrio cholera & 3 & 19.5 & 21.5 & $20 \pm 1.04$ \\
Bacillus cereus & 3 & 20 & 21.5 & $21 \pm 1.32$ \\
\hline Candida albicans & 3 & 27 & 28.5 & $27 \pm 0.58$ \\
\hline
\end{tabular}

Table 3. Comparison of average inhibitory halo diameter $(\mathrm{mm})$ of various bacterial strains for aqueous extract of propolis.

\begin{tabular}{lcccc} 
Bacterial strain & Samples & Min & Max & Mean \pm SD \\
Staphylococcus aureus & 3 & 13.5 & 15 & $14.5 \pm 0.75$ \\
Escherichia coli & 3 & 3 & 4 & $3.5 \pm 0.5$ \\
\hline Vibrio cholera & 3 & 12.5 & 15 & $14 \pm 1.30$ \\
Bacillus cereus & 3 & 4.5 & 6.5 & $5.5 \pm 0.32$ \\
\hline Candida albicans & 3 & 12 & 13.5 & $13 \pm 0.75$ \\
\hline
\end{tabular}

Table 4. The content of DPPH $(\mu \mathrm{g} / \mathrm{mL})$ in aqueous and ethanol extract of propolis $(\mathrm{P}<0.05)$.

\begin{tabular}{lc} 
Sample & IC50 $\mu \mathrm{Ig} / \mathrm{mL}$ \\
Ethanol & $8 \pm 0.25$ \\
Aqueous & $45 \pm 1.75$ \\
\hline BHT & $5.1 \pm 0.19$ \\
\hline
\end{tabular}

\section{Conclusions}

In this study, both extracts showed significant antibacterial, antifungal and antioxidant activities.. The extracts may effective in other gram-positive and gram-negative bacteria as well as may effective as antioxidant in food. Therefore it can good alternative and satisfactory artificial preservatives used in the food industry today.

\section{References}

1. Simone-Finstrom M, Spivak M. Propolis and bee health: the natural history and significance of resin use by honey bees. Apidol. 2010;41:295-311.

2. Bankova V. Chemical diversity of propolis makes it a valuable source of new biologically active compounds. J ApiProduct ApiMedical Science. 2009;1:23-8.

3. Gonçalves G, Santos NP, Srebernich SM. Antioxidant and antimicrobial activities of propolis and açai (Euterpe oleracea Mart) extracts. Rev Ciênc Farm Básica Apl 2012;32:349-56.

4. Mozaffari Nejad AS, Shabani S, Bayat M, et al. Antibacterial effect of garlic aqueous extract on staphylococcus aureuses in hamburger. Jundishapur J Microb 2014;7:1-5.

5. Eslami M, Bayat M, Mozaffari Nejad AS, et al. Effect of polymer/nanosilver composite packaging on long-term microbiological status of Iranian saffron (Crocus sativus L.). Saudi J Biol Sci 2016;23:341-7.

6. Kamkar A, Ardekani MRS, Shariatifar N, et al. Antioxidative effect of Iranian Pulicaria gnaphalodes L. extracts in soybean oil. South Afr J Bot 2013;85:39-43.

7. Heshmati A, Azizi M, Ghadimi S. Influence of ethanol and methanol extracts of walnut leaf and green hull on saccharomyces cerevisiae, bacillus licheniformis and aspergillus niger in date syrup. Iran J Nutr Sci Food Technol 2016;11:81-8.

8. Hasanvand $\mathrm{H}$, Moshtaghi $\mathrm{H}$, Heshmati A, et al. Inhibitory effect of echinophora platyloba essential oil on aspergillus flavus in culture media and cheese. J Food Qual Hazards Control 2016;3:122-7.

9. Teixeira EW, Message D, Negri G, et al. Seasonal variation, chemical composition and antioxidant activity of brazilian propolis samples. Evid Based Complement Alternat Med 2010;7:307-15.

10. Salatino A, Teixeira EW, Negri G, et al. Origin and chemical variation of brazilian propolis. Evid Based Complement Alternat Med 2005;2:33-8.

11. Dashti Z, Shariatifar N, Mohammadi Nafchi A. Study on antibacterial and antioxidant activity of Berberis vulgaris aqueous extracts from Iran. Int J Pharma Sci Res 2014;5:705-8.

12. Astani A, Zimmermann S, Hassan E, et al. Antimicrobial activity of propolis special extract GH 2002 against multidrugresistant clinical isolates. Pharmazie 2013;68:695-701.

13. Orsolic N, Basic I. Water-soluble derivative of propolis and its polyphenolic compounds enhance tumoricidal activity of macrophages. J Ethnopharmacol 2005;102:37-45.

14. Bastos EM, Simone M, Jorge DM, et al. In vitro study of the antimicrobial activity of brazilian propolis against Paenibacillus larvae. J Invertebr Pathol 2008;97:273-81.

15. Nakajima Y, Shimazawa M, Mishima S, et al. Water extract of propolis and its main constituents, caffeoylquinic acid derivatives, exert neuroprotective effects via antioxidant actions. Life Sci 2007;80:370-7. 
16. Ayres DC, Marcucci MC, Giorgio S. Effects of brazilian propolis on Leishmania amazonensis. Mem Inst Oswaldo Cruz 2007;102:215-20.

17. Schnitzler P, Neuner A, Nolkemper S, et al. Antiviral activity and mode of action of propolis extracts and selected compounds. Phytother Res 2010;24:20-8.

18. Mozaffari Nejad AS, Bayat M, Ahmadi AA. Investigation of aflatoxin B1 in spices marketed in Hyderabad, India using ELISA method. J Pure Appl Microbiol 2013;7:3219-23.

19. Jalali H, Mozaffari Nejad AS, Ebadi AG, et al. Ethnobotany and folk pharmaceutical properties of major trees or shrubs in northeast of Iran. Asian J Chem 2009;21:5632-8.

20. Stefanini MB, Figueiredo RO, Ming LC, et al. Antimicrobial activity of the essential oils of some spice herbs. Acta Hort 2003;597:215-6.

21. Valgas C, Souza SM, Smânia EF, et al. Screening methods to determine antibacterial activity of natural products. Braz J Microbiol 2007;38:369-80.

22. Klancnik A, Piskernik S, Jersek B, et al. Evaluation of diffusion and dilution methods to determine the antibacterial activity of plant extracts. J Microbiol Methods 2010;81:121-6.

23. Cuendet M, Hostettmann K, Potterat O. Iridoid glucosides with free radical scavenging properties from Fragrea blumei. Helv Chim Acta 1997;80:1144-51.

24. Wu N, Fu K, Fu YJ, et al. Antioxidant activities of extracts and main components of Pigeonpea [Cajanus cajan (L.) Millsp.] leaves. Molecules 2009;14:1032-43.

25. Musa TN, Salih NM, Ulaiwi WS. Detection of some active compounds in aqueous and ethanolic extracts of iraqi propolis and examine their antibacterial effects. Pak J Nut 2012;11:83-7.

26. da Silva KR, Mathias FT, Dutra KA, et al. Antimicrobial activity from a brazilian propolis oily extract compared with other propolis extracts. Rev Ciênc Exatas Nat 2010;12:327-38.

27. Cottica SM, Sawaya AC, Eberlin MN, et al. Antioxidant activity and composition of propolis obtained by different methods of extraction. J Braz Chem Soc 2011;22:167-71.

28. Hegazi AG, Abd El Hady FK. Egyptian propolis: 3. Antioxidant, antimicrobial activities and chemical composition of propolis from reclaimed lands. Z Naturforsch C 2002;57: 395-402.

29. Bulbul IJ, Nahar L, Ripa FA, et al. Antibacterial, cytotoxic and antioxidant activity of chloroform, n-hexane and ethyl acetate extract of plant Amaranthus spinosus. Int J PharmTech Res 2011;3:1675-80. 